\title{
INTRODUCTION
}

\section{Anthropological perspectives and policy implications of climate change research}

\author{
John Magistro ${ }^{1, *}$, Carla Roncoli ${ }^{2, * *}$ \\ ${ }^{1}$ International Development Enterprises, 10403 West Colfax Avenue, Suite 500, Lakewood, Colorado 80215, USA \\ ${ }^{2}$ Department of Anthropology, University of Georgia, Athens, Georgia 30602, USA
}

\begin{abstract}
This paper highlights the relevance of anthropological research to climate science. It suggests that localized scales of analysis, that have been the hallmark of anthropology, can complement global modeling exercises that cannot fully capture the complexities of real life decisions. Community and culture are key dimensions that mediate the interaction between humans and climate. Anthropology has a long-standing tradition of studying vulnerability and adaptation to environmental stresses. Political economy and political ecology approaches contextualize climate risk, highlighting the need to integrate climate products with policy solutions. Microanalyses of risk management and decision-making strategies can bring science and policy closer to the needs of vulnerable groups. Tools and insights from cognitive anthropology also facilitate communication of climate information by ensuring consistency with local knowledge frameworks.
\end{abstract}

KEY WORDS: Drought $\cdot$ Vulnerability $\cdot$ Seasonal forecasting

Resale or republication not permitted without written consent of the publisher

In April 1999, a group of US-based anthropologists and social scientists convened 2 panel sessions at the annual meeting of the Society for Applied Anthropology (SfAA) held in Tucson, Arizona, entitled Social Science Dimensions and Policy Contributions to Climate Change Research. The first session was specifically devoted to a series of papers addressing climate change impacts on the African continent. The second focused attention on how local community scales of analysis that serve as the hallmark of anthropological research could be more effectively linked to broader global and regional scales of climate research that characterize current research paradigms on climate change modeling of societal impacts. Panelists generally concurred that a wide gulf exists between the positivist, computer-generated, quantitative methods of research and global scales of analysis among climate change scientists and the more contextual interpretive and qualitative approaches that characterize much of social science research. Anthropological emphasis on

E-mails:

*jmagistro@ideorg.org, ${ }^{* *}$ croncoli@gaes.griffin.peachnet.edu micro-locality and household dynamics, rather than on regional and global processes, has also contributed to its relative marginality from contributions to policy science formulation within the IPCC on strategies for climate change mitigation and human adaptation. Thus the objective of the papers delivered at the SfAA meeting was to document current, relevant case studies on human adaptive response to extreme climate events in various parts of the world and to explore the implications of such response, involving locally based systems of knowledge and perception on climate phenomena, for more informed guidance among critical policy decision-making bodies such as the IPCC.

\section{BRIDGING SCALES OF ANALYSIS: FROM GLOBAL SPACE TO LOCAL PLACE}

In attempting to bridge global analyses on climate change with locally identifiable processes of community response and perception on climate, one may ask how an anthropological focus on locality can be made relevant to current scientific methods that privilege 
global biophysical and environmental processes over sociocultural and political variables. The report proceedings of 23 developing country social scientists at a recent International Human Dimensions Program on Global Environmental Change (IHDP)/Global SysTem for Analysis, Research and Training (START)-sponsored human dimensions workshop held in Bonn suggests that local spatial scales of analysis on human climate change impacts could complement global modeling exercises that often obscure such local level impacts:

'... the emphasis on largely aggregating computerised models ... and the large scales of the models, was judged by many as being relatively marginal to the day-to-day human dimensions research requirements on the ground in these regions. Local research is often the most relevant and needed to validate and verify the information derived from such models' (Shaw \& Wild 1998, p. 8).

The report goes on to conclude that integrated regional assessments 'must give attention to special kinds of places and people that are not distinctively regional in character' (Shaw \& Wild 1998). This critical conclusion particularly resonates among social scientists working at smaller spatial scales, who would argue that special kinds of places and people (i.e. 'community') are all too often obfuscated in many of the integrated climate impact assessments currently in vogue under national and international climate research programs. Core defining features of community, such as culture, that critically shape human interactions with the environment, appear to be given short shrift in terms of an adequate description or theorization in relation to global change processes (Proctor 1998).

A number of social scientists have called attention to the issue of scale in attempting to bridge global and local levels of analysis on human dimensions research (Glantz 1992, Stern et al. 1992, Ribot et al. 1996, Smithers \& Smit 1997). In general, they call for finer levels of resolution and analysis of spatial and temporal processes of human-climate interaction. It is only now being recognized in global change circles that micro-analytical perspectives on human-climate interaction could be of utility in establishing symmetry and complementarity across spatial scales, linking the global to the local:

\footnotetext{
'Although the atmosphere is global, understanding of the biosphere may need to be built up from knowledge at smaller spatial scales, such as ecosystems or biomes. Thus, knowledge of global change requires ways to understand relationships across spatial scales' (Stern et al. 1992, p. 32).
}

Particularly with respect to integrated climate impact assessments, a more localized, detailed understanding of a given geographical setting reflects the complexity of real life decisions and situations and ani- mates what are often abstract, quantified models of human dimensions research. The coarse resolution of global- and regional-scale climate change models in predicting or assessing human impacts is echoed by Downing (1992, p. 6), who notes, 'low confidence in regional changes and the large grid scale of most GCM models limit their direct usefulness in local impact assessments.'

\section{LINKING SCIENCE AND SOCIETY: POLITICAL AND CULTURAL DIMENSIONS OF CLIMATE RESEARCH}

Bridging analytical scales is not a new endeavor in anthropology. Human and ecosystem interactions have been a crucial dimension of anthropological theories of what drives culture and behavior. Among the first to systematically apply the ecosystem concept in anthropology was Emilio Moran, who is among the few anthropologists actively involved in the IPCC. His recent work combines remote sensing and ethnographic field methods of data gathering and analysis to gain a detailed understanding of socioeconomic and biophysical processes associated with deforestation in the Amazon basin (Moran \& Liverman 1998). A contributor to this CR SPECIAL, Robert Rhoades, has spearheaded an interdisciplinary methodology to link mountain farming systems with climate variation issues in the wider Hindu Kush/Himalaya region (Rhoades 1997). This approach aims to place mountain farming systems into a comparative framework for the purposes of assessing sustainability and resilience at scales from the household to the eco-region. Focusing on another specific ecosystem, that of Lake Titicaca in Peru, Orlove (2001) documented how climate-related fluctuations in lake levels constrain land tenure and foster tensions between local communities and state agencies. This work epitomizes how anthropology redefines geographic space in ways that not only reveal interconnections across scales but also a domain layered with moral meanings, social claims, and political pressures. Thus, the 'local' is shown to be as diverse and complex a realm as the 'global'. These 3 studies epitomize how anthropology can provide a prism for examining such complexities at the regional as well as at the local scale.

This insight informs recent empirical and theoretical work on vulnerability to climate shocks by anthropologists and other social scientists (Blaikie et al. 1994). According to this perspective, which builds on the seminal work of development economists Drèze \& Sen (1989), regions may be redefined as the 'location of vulnerable populations rather than as inherently vulnerable due to resource and infrastructural constraints' (Downing et al. 1996, p. 190). This social vulnerability 
results from the interaction of regional climate variation with human ecology, political economy, and resource entitlements, that is the bundle of formal and informal rights, claims, and capabilities that shape access to food and assets. Within localities, wealth, caste, ethnicity, age, and gender shape risk exposure and reproduce differential vulnerabilities over time. At the same time, adaptive responses articulate with global forces, including population movements, political turmoil, environmental restrictions, trade agreements, and economic stabilization programs.

An appreciation of the importance of these relationships makes it more difficult to isolate the implications of climate variability from other historical and contextual factors. This understanding is central to the work by anthropologists involved in interdisciplinary research on the potential applications of climate predictions, some of whom are also contributors to this CR SPECIAL (Broad 2000, Nelson \& Finan 2000, Roncoli et al. 2000). They warn that a narrow focus on forecast dissemination as a way of reducing vulnerability to climate related risk may divert from broader-level development efforts to bolster public resiliency by improving local infrastructural and institutional capacities (Broad 2000). They also point to the paradox inherent in donor-driven efforts to promote forecast use while also fostering development approaches that de-emphasize the public sector, weakening its ability to support citizens in coping with climate shocks (Broad \& Agrawala 2000, Roncoli et al. 2000).

Evidence from a variety of contexts shows that political considerations shape the way climate information is used in making decisions, developing policy, allocating resources, and managing risk (Glantz 1996, Broad 2000, Broad \& Agrawala 2000, Nelson \& Finan 2000). But political landscapes are characterized by a diversity of stakeholders, including government, donors, business, labor, and consumers. The fact that these groups have different resources at their disposal and even contradictory interests at stake further complicates assessments of climate impacts and of potential benefits of climate forecasts. Climate scientists may be called upon to provide information or make decisions that may favor one group over another (Pfaff et al. 1999). The probabilistic nature of climate forecasts may lend itself to manipulation by certain groups, who may magnify or minimize uncertainty according to what serves their interests. Joint efforts by anthropologists, sociologists, economists, and political scientists can help map out potential pitfalls and minimize unintended consequences of forecast dissemination, especially with regard to equity and sustainability concerns (Rayner \& Malone 1998).

In his analysis of societal impacts of El Niño-based science, Glantz (1996) invited scientists to direct their efforts not only to educate users but also to educate themselves about users and their different needs. The diversity of users - including urban and rural populations, large-scale and small-scale producers, public and private sectors, institutions and individuals, and men and women-implies that different forecasting parameters and communication approaches are called for. Even within a single institution, a plurality of interests may exist and result in competing information priorities (Thompson \& Rayner 1998, Orlove \& Tosteson 1999). It is recognized that climate science does not always address the questions citizens are asking (Kempton et al. 1995, Glantz 1996). In West Africa seasonal forecasts refer to total rainfall quantity, while timing of onset and end of the rainy season and distribution of rainfall during the season are more relevant parameters for African farmers (Ingram et al. 2001). East African pastoralists are more concerned with regional water availability than with precipitation per se (Mahmoud \& Little 2000). A comparative assessment of El Niño forecasts in different countries indicates that a higher level of forecast reliability is required to overcome institutional resistance to risk action (Orlove \& Tosteson 1999). Anthropological tools for decision making analysis can help identify what information is needed, at what point in the decision process it should be available, and to what behavioral outcomes it may lead.

Even when science addresses users' information needs, dissemination and assimilation of climate forecasts may be hindered by inappropriate idiom, medium, and timing (Nelson \& Finan 2000, Otterstram 2000, Roncoli et al. 2000). But effective communication requires more than getting the message out in the local language. As information circulates among different stakeholders, lack of fit in institutional culture or cognitive frameworks may result in incorrect interpretations (Orlove \& Tosteson 1999). Kempton et al. (1995) illustrate the shifts in meaning that occur as information moves from science journal to news reports to agency memos to what individuals finally retain. Their research on lay public understanding of global warming indicates that people filter and absorb information in terms of pre-existing cultural models, such as ideas about nature's fragility and how humanity should interact with it. It is essential to understand these models and the causal relationships they posit in order to communicate climate information in ways that generate positive action (Kempton et al. 1995, Thompson \& Rayner 1998). Anthropological assessments of forecast impacts document the importance of cultural meanings, collective myths, and social memory in shaping public and private responses (Broad 2000, Nelson \& Finan 2000, Otterstrom 2000). But beyond shared norms, attention to and assimilation of new knowledge 
by individuals is also directed by what buttresses their interests and ideologies (Kempton et al. 1995).

An appreciation of the importance of what people know and how they think about climate has generated a great deal of interest in ethno-meteorological knowledge. Some studies focus on testing the scientific validity of farmers' forecasts (Orlove et al. 2000), others seek to identify whether and how indigenous and scientific forecasting knowledge can be integrated (Roncoli et al. in press). Clearly, Western-trained scientists and farmers from developing countries operate in distinct cognitive frameworks that hold different views about the relationships between nature, society, and knowledge. Yet such divergences need not spell incompatibility: users may combine elements of different knowledge systems without striving for overall consistency (Roncoli et al.in press). Current anthropological theories stress pluralism, ambiguity, and fluidity as constitutive features of most cultural systems. Neither indigenous cultures nor scientific circles are repositories of uncontested, unchanging, and uniformly held knowledge (Agrawal 1995). Recent ethnographic research focuses on the climate science community, illustrating how it too encompasses a multiplicity of worldviews (Lahsen 1999). It suggests that cultural values shape not only the reception of climate information by the lay public, but also evaluations of its credibility and relevance by experts. Different ideas about the relationship of science and technology and about the role of science in society underlie assessments of what constitutes 'good science' and what is worth making public knowledge (Lahsen 1999). Cultural meanings are crucial dimensions not only of community-level understandings and responses but also of global scientific and political debates surrounding climate variation.

\section{CONTRIBUTIONS TO THIS CR SPECIAL}

The papers in this CR SPECIAL illustrate how anthropological understandings of the cultural, economic, and political context of human adaptation can inform policy related to climate variability and change. As a set, they offer an opportunity to examine the salient themes identified above in a comparative perspective. Drawing largely from interdisciplinary research, they also demonstrate the benefits of combining qualitative and quantitative methods. The contributions cluster around 3 key themes, including perceptions and knowledge of climate variability, human adaptation and social vulnerability to inter-annual and seasonal climate shocks and the interconnections between global, regional, and local scales of analysis. The CR SPECIAL emphasizes the importance of considering human adaptation to seasonal and inter- annual climate variability as a core component integral to, not separate from, research on global climate change. Glantz (1992) has underscored the importance of this observation (see contribution by Magistro \& Lo).

Malone \& Rayner situate the CR SPECIAL within the broader political and ethical context of North-South dialogue on social justice and equity in the international debate on global warming. They point out that current climate change research is largely defined and interpreted within a purely 'objective', descriptive scientific approach that allows little room for the subjective or interpretive frames of knowledge that characterize much of social science research. Contrasting research traditions and epistemologies of knowledge lie at the core of divergent scales of analysis, the weak integration of macro analysis that predominates in global climate change circles, and micro-analytical interpretations of local adaptation that underpin much of social science research. Malone \& Rayner conclude that current scientific paradigms on climate change research do not adequately address human dimensions of adaptation and vulnerability to climate events.

The contribution by Galvin et al. best represents a recent hybridized approach to integrate natural and social science research methods in linking disparate scales of analysis in climate change research. Addressing the concerns of Malone \& Rayner, Galvin et al. link descriptive biophysical and contextual data that also succeeds in bridging local and regional scales of analysis. Human response to drought conditions in 1997 and heavy El Niño rains in 1998 among Maasai herders in northern Tanzania is assessed by correlating locallevel survey data on herd movements and livelihood coping strategies to changes in composition of remotely sensed vegetative biomass. The authors work represents an innovative interdisciplinary approach to global change research that is effective in linking social science data grounded in anthropological field observation and qualitative research methods with quantitative biophysical data on the seasonal change in NDVI composition using a hierarchical cluster analysis. By linking both research methods, Galvin et al. are able to extrapolate the economic consequences of the 1997 and 1998 climate events among the Maasai beyond the local community to a broader regional scale. This work provides a model approach to integrative climate change research that successfully links contrasting research methods and scales of analysis. The authors conclude that adequate advance warnings could help pastoralists change their livestock practices to adapt to climate variability in more effective and sustainable ways.

The local impacts of the 1997-1998 El Niño floods and heavy rainfall among herders in the Somali borderlands with northern Kenya are also explored by Lit- 
tle et al. This research documents differential response among pastoralists and extends the conventional context of climate variability beyond its biophysical parameters to understand climate anomaly as a socioeconomic and political phenomenon as well. The authors stress the key role of spatial diversification as a mitigation strategy, arguing that pastoral response to El Niño rains and the debilitating effects of livestock mortality and distress sales are largely determined by constraints in herder mobility and access to markets as a result of civil strife and livestock raiding. They point out how behavioral response to climate variability may trigger civil strife and social conflict in the form of extensive livestock raiding to recover herd losses. Little et al. note that the frequency of climate anomaly is critical in shaping human behavior. The rare occurrence of an El Niño flood had little impact in altering herder coping strategies in 1998.

The political context of climate variability is echoed in several contributions to this CR SPECIAL. Finan \& Nelson place the El Niño/Southern Oscillation drought of 1998 in Ceará, northeast Brazil, within the historical context of public and private responses to frequent drought in the region. Similar to the work of Little et al., the authors highlight how drought differentially impacts the rural population by prompting higher levels of distress sales of livestock among the poor, while resource-rich individuals are able to withstand the adverse effects of climate shock. Most importantly, they illustrate how government policy on drought relief in the form of public employment, food aid, and water delivery reinforces longstanding patterns of local clientelism by conferring advantage to local political elites over the rural masses of resource-poor farmers in ways that hinder proactive public response. They also highlight how public discourse about climate variability can shape mitigation policies and resource access, for instance, limiting farmers access to credit.

Roncoli et al. also bring to our attention the variegated nature of human adaptation and response to climate extremes. Based on intensive household-level data collection among the Mossi of Central Plateau following the 1997 drought in Burkina Faso, this work emphasizes local-level variation in household ability to cope and recover from food crises. Household resource endowments shape one's choice of coping strategies and attendant impacts. Consistent with the research of Finan \& Nelson, the authors point to livelihood diversification and social capital, in the form of migration remittances and support from relatives, as key dimensions of adaptation to climate shocks, especially among the rural poor. The research also illustrates that an emphasis on immediate coping obscures the fact that adaptive strategies assume costs that are often borne by the less privileged, and that may result in increased vulnerability to climatic risk. Women are shown to play important roles in household livelihood and risk management, a fact that is contributing to the refashioning of intro-household gender relations.

Magistro \& Lo present a regional case study from the northern Senegal wetlands emphasizing the nature of inter-annual and seasonal climate variability during the past century and historical patterns of human vulnerability and adaptation to drought and flooding along the Senegal River. Since the Sahelian drought of the early 1970s, the region has witnessed a secular decline in precipitation, heightened food insecurity, and a general decline in traditional riparian agroecology that relies upon an annual flood of the seasonal wetlands. The result has been the introduction of 2 dams on the river in the 1980s and an interstate river basin development strategy to develop hydroelectricity, irrigation farming, and a navigable watercourse on the river. The future management of a high dam at Manantali, Mali, will be significantly shaped by policy debate and political interpretations of the historical record on inter-annual and seasonal variability of rainfall and hydrological flow data on the river. Two hydrological time flow series illustrate the importance of climate variability for the region and are now being used by policy makers to weigh the costs and benefits of competing water use scenarios for end users downstream.

A final theme common to several contributions in the CR SPECIAL is the critical role of local perception and farmer/herder knowledge of climate change. Little et al. touch upon indigenous perceptions of climate variability that extend beyond rainfall to knowledge of seasonal vegetation and herd mobility. Vedwan \& Rhoades explore local knowledge of climate among apple growers in Himachal Pradesh in northern India. They show how farmers interpret climate change in relation to the annual growth cycle of apples that are highly sensitive to the onset, duration, and intensity of snowfall in the region. According to the apple growers, noticeable changes in these climate variables have resulted in a significant decline in the region's apple industry in recent years. By attributing the cause of this decline to a 'natural' phenomenon such as climate change (unlike agricultural scientists, who attribute it to planting choices), farmers are able to instill a greater sense of entitlement into their claims to government assistance.

In conclusion, several observations may be drawn from these studies with respect to anthropological contributions to policy on human adaptation to climate change. Both Vedwan \& Rhoades and Roncoli et al. propose that policy measures to mitigate climate change impacts incorporate more local knowledge of climate-crop interactions. Roncoli et al. and Finan \& Nelson argue that farmer access to modern climate 
forecasting information is not sufficient to mitigate against the adverse impacts of climate. Farmers may lack the resources to optimally respond to forecasts to prepare for climate shocks. Dissemination of climate information must be supported by an integrated approach that seeks to improve access to needed agricultural technologies and services that will bolster the productivity and flexibility of resource-poor farmers and herders in order to carry them through the worst periods of climate perturbation. This, in turn, must be supported by development policies that facilitate the sustainability of local rural livelihoods such as facilitating seasonal mobility and grazing land access among livestock producers, increasing intensification of high value crops for regional and extra-local markets, and supporting the profitability of non-farm economic activities. It is hoped that anthropological and related social science research such as that represented in this CR SPECIAL may offer new insights that shape climate change policy and build on the adaptive capacity of rural livelihoods while also taking into account the dilemmas and tradeoffs that are entailed.

Acknowledgements. The authors wish to thank Mike Hulme and the anonymous reviewers of the papers for this CR SPECIAL. The literature reviewed in this introduction reflects the current state of anthropological research on climate change and variability among US-based anthropologists and does not represent state-of-the-art contributions from the UK or other parts of the world.

\section{LITERATURE CITED}

Agrawal A (1995) Dismantling the divide between indigenous and scientific knowledge. Dev Change 26:413-439

Blaikie P, Cannon T, Davis I, Wisner B (1994) At risk: natural hazards, people's vulnerability, and disasters. Routledge, London

Broad K (2000) El Niño and the anthropological opportunity. Pract Anthrop 22:20-23

Broad K, Agrawala S (2000) The Ethiopia food crisis-uses and limits of climate forecasts. Science 289:1693-1694

Downing TE (1992) Climate change and vulnerable places: global food security and country studies in Zimbabwe, Kenya, Senegal and Chile. Environmental Change Unit, University of Oxford

Downing TE, Watts MJ, Bohle HG (1996) Climate change and food insecurity: towards a sociology and geography of vulnerability. In: Downing TE (ed) Climate change and world food security. Springer-Verlag, Berlin, p 206

Drèze J, Sen AK (1989) Hunger and public action. Clarendon, London

Glantz MH (1992) Global warming and environmental change in Sub-Saharan Africa. Global Environ Change 2:183-204

Glantz MH (1996) Currents of change: El Niño's impacts on climate and society. Cambridge University Press, Cambridge

Ingram K, Roncoli C, Kirshen P, Flitcroft I (2001) Opportunities and constraints to using seasonal precipitation forecasting to improve agricultural production systems and livelihood security in the Sahel-Sudan region: a case study of Burkina Faso. In: Proceedings of the International Forum on Climate Prediction, Agriculture, and Development. New York, April 26-28, 2000. International Research Institute for Climate Prediction, Palisades, NY, p 265-277

Kempton W, Boster J, Hartley J (1995) Environmental values in American culture. MIT Press, Cambridge

Lahsen M (1999) The detection and attribution of conspiracies: the controversy over Chapter 8. In: Marcus GE (ed) Paranoia within reason: a casebook on conspiracy as explanation. University of Chicago Press, Chicago, p 111-126

Mahmoud H, Little P (2000) Climatic shocks and pastoral risk management in northern Kenya. Pract Anthropol 22: 11-14

Moran E, Liverman D (eds) (1998) Peoples and pixels: remote sensing and social science. National Academy Press, Washington, DC

Nelson DR, Finan TJ (2000) The emergence of a climate anthropology in northeast Brazil. Practicing Anthropol 22: $6-10$

Orlove B (2001) Lines in the water: nature and culture at Lake Titicaca. University of California Press, Berkeley

Orlove B, Tosteson J (1999) The application of seasonal to interannual climate forecasts based on El Niño-Southern Oscillation (ENSO) events: lessons from Australia, Brazil, Ethiopia, Peru, and Zimbabwe. Berkeley Workshop Environ Polit Working Pap 99 (3), Institute of International Studies, University of California, Berkeley

Orlove BS, Chiang JH, Cane MA (2000) Forecasting Andean rainfall and crop yield from the influence of El Niño on Pleiades visibility. Nature 403:68-71

Otterstrom S (2000) Variation in coping with El Niño droughts in northern Costa Rica. Pract Anthropol 22:15-19

Pfaff A, Broad K, Glantz MG (1999) Who benefits from climate forecasts? Nature 397:645-646

Proctor JD (1998) The meaning of global environmental change: retheorizing culture in human dimensions research. Global Environ Change 8:227-248

Rayner S, Malone E (eds) (1998) Human choice and climate change. Battelle, Columbus

Rhoades R (1997) Pathways to a sustainable mountain agriculture for the 21st century: the Hindu Kush experience. International Centre for Integrated Mountain Development, Kathmandu

Ribot JC, Magalhães AR, Panagides SS (eds) (1996) Climate variability, climate change and social vulnerability in the semi-arid tropics. Cambridge University Press, Cambridge

Roncoli C, Ingram K, Kirshen P (2000) Can farmers of Burkina Faso use seasonal rainfall forecasts? Pract Anthropol 22: 24-28

Roncoli C, Ingram K, Kirshen P (in press) Reading the rains: local knowledge and rainfall forecasting among farmers of Burkina Faso. Soc Nat Resour

Shaw RV, Wild U (eds) (1998) IHDP/START International human dimensions workshop. IHDP Proceedings No. 1. August 8-21, 1998, Bonn. IHDP/START, Bonn

Smithers J, Smit B (1997) Human adaptation to climate variability and change. Global Environ Change 7:129-146

Stern PC, Easterling WE (eds) (1999) Making climate forecasts matter. National Academy Press, Washington, DC

Stern PC, Young OR, Druckman D (eds) (1992) Global environmental change: understanding the human dimensions. National Academy Press, Washington, DC

Thompson M, Rayner S (1998) Cultural discourses. In: Rayner S, Malone E (eds) Human choice and climate change: the societal framework. Battelle, Columbus, p 265-343 